\title{
SURGICAL TREATMENT OF PATELLAR TENDON PAIN IN ATHLETES
}

\author{
S. ORAVA, MD, L. OSTERBACK, MD* and M. HURME, MD** \\ Dept. of Surgery, K-P Central Hospital, Kokkola, Finland \\ Clin. of Sports Med., Medirex, Kokkola and Clin. of Sports Med., Deaconess Institute, Oulu \\ *Research Unit for Sports \& Physical Fitness, Jyväskylä, Finland \\ **Dept. of Surgery, City Hospital, Turku, Finland
}

\begin{abstract}
A series of surgically treated patellar tendon lesions among athletes is presented. The material was collected during 5 years from three sports injury clinics and from two hospitals. During this period the authors treated about 150 cases of jumper's knee, of which 34 cases were treated by operation. The athletes were mostly volley ball players, jumpers or runners. The operation revealed a necrotic focus of the patellar tendon in 21 cases, the retinaculum was thick and adherent in 16 patients and an exostosis of the patellar insertion was seen in two cases. The necrotic areas were excised, the thick and adherent retinaculum was divided and the exostoses were excised and drilled. Surgical treatment of chronic patellar tendon pains may give good results in selected cases.
\end{abstract}

Key words: Surgical treatment, Patellar tendon, Sports injury

\section{INTRODUCTION}

Patellar tendon pains are among the most common overuse injuries seen in competitive athletes (Orava, 1980 and 1985; Kvist et al, 1985). Sports events with repetitive extension movements, such as jumping, volley ball and sprinting are said to cause the so-called "jumper's knee" - syndrome (Krahl, 1972; Ljungqvist, 1977; Schneider, 1981). Jumper's knee is understood to be a local degeneration of the proximal patellar tendon near the lower pole of the patella (Blazina et al, 1973; Krahl, 1980). Associated with this there may be pain located at the patellar tendon, its distal and proximal insertion as well as at the quadriceps tendon insertion at the superior pole of the patella.

The treatment of these chronic conditions may be difficult. Elimination of patellofemoral malalignments, faulty training technique and physical therapy with stretching and strengthening exercises of the quadriceps muscle have been recommended (Roels et al, 1978; Jakob and Segesser, 1980; Martens et al, 1982; Peterson and Renström, 1983). Recently local injection with glycosaminoglycanpolysulphate has been reported with promising results (Kvist et al, 1985). Corticosteroids, on the other hand, are not recommended because of the possible harmful effects on the tendon (Krahl, 1972; Ismail et al, 1978; Tarsney, 1981; Ferretti et al, 1983). Operative treatment has been used in chronic or severe cases and the results are usually good (Ljungqvist, 1977; Krahl, 1980; Ferretti et al, 1983; Martens et al, 1982;

In this report a series of patients with operatively treated patellar tendon pain is presented.

\section{MATERIAL AND METHODS}

The material was collected over 5 years from three sports injury clinics and from two hospitals.

Address for correspondence:

Dr. S. Orava, MD

Department of Surgery

K-P Central Hospital

Kokkola

Finland
During the period studied, the authors diagnosed and treated about 150 cases of jumper's knee. Some of the surgically treated patients were referred to the authors by other physicians, after conservative treatment had proved to be unsuccessful.

The cases operated on consisted of six female and 28 male athletes. The female athletes were somewhat younger, 20.7 years on average (range 17-26 years), than the male athletes (mean age 27.7 years; range $17-39$ years). Sporting details of the athletes operated on, are shown in Table I. About one third of the surgically treated athletes were volley ball players although they also participated in other sports.

TABLE I

The athletes operated upon classified by sports event

\begin{tabular}{lrc}
\hline Sports event & N & $\begin{array}{c}\text { Mean age } \\
\text { (yrs) }\end{array}$ \\
\hline Volley ball & 10 & 30.5 \\
High jump, long jump, triple jump & 7 & 22.0 \\
Distance running & 7 & 26.2 \\
Decathlon, heptathlon & 4 & 24.1 \\
Sprint & 3 & 22.3 \\
Javelin, shot put & 2 & 28.9 \\
Soccer & 1 & 21.0 \\
\hline Total & 34 & 26.1 \\
\hline
\end{tabular}

Eleven of the injuries developed acutely either by twisting ( 8 cases) or by contusion ( 3 cases). The rest (17 cases) were typical overuse injuries without any preceding trauma.

\section{PREOPERATIVE SYMPTOMS AND SIGNS}

Pain in the lower part of the patella with activity was the most common symptom. In some cases diffuse pain was felt over the whole of the patellar tendon. Twenty-five patients had localised tenderness over the inferior pole of the patella. In two cases there was a palpable nodule in the tendon insertion. In seven cases the tendon was thicker 
than on the other side and in two cases there was excessive lateral movement of the patella. The degree of disability has been estimated in Table II.

TABLE II

The degree of disability before the operation

\begin{tabular}{lrr}
\hline Degree of disability & N & $\%$ \\
\hline Pain with normal activities & 7 & 21 \\
No symptoms with normal activity but sport was impossible & 16 & 47 \\
Reduced sporting activity & 11 & 32
\end{tabular}

\section{PREOPERATIVE INVESTIGATIONS}

Ultrasound was used in the investigation of 11 cases. One of these examinations was completely normal, in three cases a clear focus could be seen and in seven cases the patellar tendon was thicker than on the opposite side. Twenty patients had radiographs taken of which 12 were normal. In seven cases the tendon was seen to be thicker than normal and in one case an area of degeneration was suspected.

\section{PREOPERATIVE TREATMENT}

On average the symptoms had been present for 1.7 years before operation. The period of conservative treatment varied from six months to four years. All of the patients had received anti-inflammatory medication. Physiotherapy and injections of corticosteroids and glycosamino-glycanpolysulphate (Arteparon ${ }^{\circledR}$ ) were used frequently (Table III).

TABLE III

Preoperative treatment

\begin{tabular}{lcr}
\hline Treatment & $\mathrm{N}$ & $\%$ \\
\hline Physiotherapy ( $>10$ times) & 28 & 82 \\
Glycosaminoglycanpolysulfate-injections (Arteparon $\left.{ }^{\otimes}\right)$ & 21 & 62 \\
( $>1$ inj.) to the paratenon & 26 & 76 \\
Corticosteroid-injections $(>1$ inj.) & & \\
\hline
\end{tabular}

\section{SURGICAL TECHNIQUE}

The operations were done using spinal (11 cases) or local anaesthesia $(15-20 \mathrm{ml} 1 \%$ lignocaine). A tourniquet was used if the diagnosis was unclear and the exploration might be required to be extensive. The patient was supine and the affected knee was slightly flexed. A transverse skin incision was made across the tendon insertion at the lower pole of the patella. The precise surgical technique depended on the operative finding. If there was a necrotic focus in the tendon this was excised. If the retinaculum was thick and adherent it was divided. The retinaculum was partially resected anteriorly and cleaved distally. In the case of a bony exostosis, it was excised from the lower pole of the patella and several holes were drilled in the lower pole of the patella using a $2 \mathrm{~mm}$ drill.

\section{POSTOPERATIVE TREATMENT AND REHABILITATION}

Plaster immobilisation was not used in this series. Patients used walking sticks for 2-4 days postoperatively following which full weight bearing was allowed. Straight leg raising exercises were taught preoperatively and started one to three days after the operation. Elastic compression bandage was used for one week to prevent the development of a haematoma and oedema. Active exercises of the thigh and calf muscles were started as soon as possible. Electrical stimulation was used if muscle atrophy became pronounced. Training in water was allowed in the third week, cycling in the fourth week and weight lifting (avoiding maximal flexion of the knee) in the sixth week. Light running was usually possible two months after the operation and jumping exercises introduced gradually after that. There was considerable individual variation in the rehabilitation activities, depending on the sport and the operative findings. Training at maximum level was usually not possible for three to four months after the excision of a degenerative focus.

\section{RESULTS}

The operation revealed a necrotic focus in 21 cases (Table IV). It was situated within or at the posterior aspect of the tendon. The retinaculum was thick and adherent in 16 patients and an exostosis could be seen in the insertion in two cases (Table IV). In 10 operations a vacuum drainage tube was used and removed the following morning. No complications occurred postoperatively.

TABLE IV

Operative treatment

\begin{tabular}{|c|c|c|}
\hline Type of treatment & $\mathbf{N}$ & $\%$ \\
\hline Excision of necrotic focus & 21 & 62 \\
\hline Excision of retinaculum & 16 & 47 \\
\hline $\begin{array}{l}\text { Excision of exostosis and drilling } \\
\text { of patella }\end{array}$ & 2 & 6 \\
\hline
\end{tabular}

The excised focus was microscopically examined in 6 cases. The typical microscopical finding was degenerated, fibrotic scar tissue with thick-walled new capillaries.

The mean period of follow-up after the operation was 4.5 years ( 6 months -8 years). The results of the operation are shown in Table V. Two patients did not benefit from the operation and one of these patients was operated upon a second time. In the first operation a degenerative focus was excised but the retinaculum was not divided. In the second operation the thickened retinaculum was divided and excised with a very good postoperative result. The other patient will probably return to surgery in the future. The result of the operation was very good in 23 cases $(68 \%)$. Nine of the athletes operated on still had some postoperative pain while exercising $(26 \%)$. The benefit from the operation could usually be noted two to three months after surgery.

TABLE V

Surgical outcome

\begin{tabular}{lrr}
\hline & N & $\%$ \\
\hline Symptoms during normal activities & 0 & 0 \\
Sports participation not possible & 2 & 6 \\
Reduced sporting activity & 9 & 26 \\
Asymptomatic & 23 & 68 \\
\hline
\end{tabular}




\section{DISCUSSION}

Jumper's knee is not very easy to diagnose because many other overuse syndromes occur in the same area with similar symptoms (Williams, 1980; Orava, 1980; Blazina et al, 1973). The severity of jumper's knee before operation usually prevents active training and competition. If the athlete ignores the symptoms and continues hard training, he may even suffer a total rupture of the tendon (Tarsney, 1981; Krahl, 1972; Franke, 1977; Vainionpää et al, 1985). The avulsion of the tibial tuberosity may appear after minimal trauma in youth (Hand et al, 1971; Bowers, 1981). Even among adults avulsion fractures may appear in the distal insertion of the patellar tendon (Franke, 1977; Hand et al, 1971).

Approximately $16-17 \%$ of our patients with patella tendon pain needed surgery. This figure was calculated on the basis of the number of patients seen and treated by the authors.

It is usually considered sufficient to excise the degenerate focus and the same observation was made in this study with further surgical treatment seldom being needed. The same method has been widely recommended (Sala, 1985; van der Ent and de Baere, 1985; Ljungqvist, 1977). The resection of the lower pole of the patella is not necessary if the bone configuration is normal (van der Ent and de Baere, 1985; Blazina et al, 1973). The postoperative use of plaster cast seems to be indicated in complete ruptures (Peterson and Renström, 1983).

A transverse incision in the direction of the skin wrinkles is recommended. Thus it is possible to explore the whole patellar tendon from a small incision. In the constrictive peritendinitis the authors have resected the retinaculum anteriorly to the patellar tendon and cleaved it distally. The removal of the retinaculum does not have to extend to the medial or lateral sides of the tendon.

A bloodless field is advisable if the exploration is extensive. The operation is easy without a tourniquet and with only local anaesthetic. Histologically the degenerated/ ruptured focus contains fibrosis, "wet tissue paper" appearance and increased number of cells with new blood vessel formation (Williams, 1980; Roels et al, 1978; Ferretti, et al, 1983; Kelly et al, 1984). When the skin is opened the focus can be palpated within the tendon. In peritendinitis and constrictive peritendinitis the retinaculum is thick comprising fibrous and connective tissue. The surface of the tendon is adherent and has lost its lustre.

To avoid a chronic jumper's knee the therapy should be started early (Kvist et al, 1985; Schneider, 1981). Medical and physical therapy should always be supplemented with rest from jumping exercises. In chronic cases when the patient's sports career seems to be in danger surgery can be considered. During the rehabilitation period the athlete should undertake remedial exercises but all kinds of jumping exercises should be avoided for several months after the operation. In the most severe cases the physician may have to advise the athlete to give up sports.

The operative treatment of patellar tendon lesions appears to be relatively painless and give good results in selected patients.

\section{References}

Blazina, M. E., Kerlan, R. K., Jobe, F. W., Carter, V. S. and Carison, G. J., 1973 "Jumper's knee". Orthop.Clin.North Amer. 4: 665-678.

Bowers, K. D., 1981 "Patellar tendon avulsion as a complication of OsgoodSchlatter's disease". Amer.J.Sports Med. 9: 356-359.

Ferretti, A., Ippolito, E., Mariani, P. and Puddu, G., 1983 "Jumper's knee". Amer.J.Sports Med. 11: 58-62.

Franke, K., Traumatologie des Sports. VEB Verlag Volk und Gesundheit. Berlin, 1977.

Hand, V., Hand, C. and Dunn, W., 1971 "Avulsion fractures of the tibial tuberosity". J.Bone Joint Surg. 53-A: 1579-1583.

Ismail, A. M., Balakrishnan, R. and Rajakumar, M. K., 1978 "Rupture of patellar ligament after steroid infiltration. A report of a case". J.Bone Joint Surg. 51-B: 503-504.

Jakob, R. P. and Segesser, B., 1980 "Quadriceps-Dehnungsübungen - Ein neues Konzept in der Behandlung der Tendinosen des Streckapparates am Kniegelenk (Jumper's knee)". Orthopäde 9: 201-206.

Kelly, D. W., Carter, V. S., Jobe, J. W. and Kerlan, R. K., 1984 "Patellar and quadriceps tendon ruptures - jumper's knee". Amer.J.Sports Med. 12: 375-380.

Krahl, H., 1980 "Jumper's knee. Atiologie, Differential-diagnose und therapeutische Möglichkeiten". Orthopäde 9: 193-197.

Krahl, H., 1972 "Typische Verletzungsmuster bei Hochspringern". Z.Orthop. 110: 789-794.

Kvist, M., Järvinen, M. and Forsskåhl, B., 1985 “Comparison of arteparon and indomethasin in the treatment of apicitis patellae and peritendinitis of ligamentum patellae in athletes" (Summary in English). Suomen Liikuntalääketiede 4: 66-73.

Ljungqvist, R., 1977 "Partial subcutaneous ruptures of the patellar tendon". Int. Congress on Sports Injuries 11-13.8. Espoo, Finland.

Martens, M., Wouters, P., Burssens, A. and Mulier, J. C., 1982 "Patellar tendinitis. Pathology and results of treatment". Acta Orthop.Scand. 53: 445-450.

Orava, S., 1980 "Exertion injuries due to sports and physical exercise". Thesis. Kokkola, Finland.

Orava, S., 1985 "Changes in the occurence of overuse injuries in athletes during ten years" (Summary in English). Suomen Liikuntalääketiede 4: 52-56.

Peterson, L. and Renström, P., 1983. Skador inom idrotten. 2nd ed., Folksam, Riksidrottsförbundet, Sweden.

Roels, J., Martens, M. C., Mulier, J. C. and Burssens, A., 1978 "Patellar Tendinitis (Jumper's knee)". Amer.J.Sports Med. 6: 362-368.

Sala, H., 1985 "Jumper's knee; diagnosis and treatment". Proc.Netherl.Orthop.Soc.Acta Orthop.Scand. 56: 450.

Schneider, P. G., 1981 "Das Patellaspitzensyndrom (PS-Syndrom). The kneecap syndrome (jumper's knee)". Dtsch.Zschr.Sportmed. 2: 27-35.

Tarsney, F. F., 1981 "Catastrophic jumper's knee. A case report". Amer.J.Sports Med. 9: 60-61.

Vainionpää, S., Böstman, O., Pätiälä, H. and Rokkanen, P., 1985 "Rupture of the patellar tendon". Ann.Chir.Gynaecol. 74: 274-276.

van der Ent, A. and de Maere, G. A. J., 1985 "Jumper's knee: results of operative therapy". Proc. Netherl.Orthop.Soc.Acta orthop.Scand. 56: 450.

Williams, J. G. P., 1980. A Colour Atlas of Injury in Sport. Wolfe Med. Publ. Ltd., London. 